\title{
Correction to: Microcella flavibacter sp. nov., isolated from marine sediment, and reclassification of Chryseoglobus frigidaquae, Chryseoglobus indicus, and Yonghaparkia alkaliphila as Microcella frigidaquae comb. nov., Microcella indica nom. nov., and Microcella alkalica nom. nov.
}

Fuquan Xie - Shengxiang Pei $\cdot$ Xiaoyun Huang •

Lina Wang • Jinyan Kou • Gaiyun Zhang $(\mathbb{D}$

Published online: 23 February 2022

(C) Springer Nature Switzerland AG 2022

Correction to: Antonie van Leeuwenhoek (2021) 114:2133-2145

https://doi.org/10.1007/s10482-021-01668-7

In the original publication of the article, the protologue for Microcella indica was incorrectly published as "nom. nov." (nomen novum). The correct protologue for Microcella indica is "comb. nov." (combinatio nova).

The original article has been corrected.

The original article can be found online at https://doi.org/ 10.1007/s10482-021-01668-7.

F. Xie $\cdot$ S. Pei $\cdot$ X. Huang $\cdot$ L. Wang $\cdot$ J. Kou $\cdot$

G. Zhang $(\bowtie)$

Key Laboratory of Marine Biogenetic Resources, Third Institute of Oceanography, Ministry of Natural Resources, Xiamen 361005, Fujian, People's Republic of China e-mail: zhgyun@tio.org.cn
Publisher's Note Springer Nature remains neutral with regard to jurisdictional claims in published maps and institutional affiliations. 